\title{
Ethylene Glycol Purification by Melt Crystallization: Removal of Short-Chain Glycol Impurities
}

Tiefeng Wang, ${ }^{\dagger} \mathrm{Xu} \mathrm{Li},{ }^{\dagger}$ Jinxiang Dong $*, \$, \dagger$

${ }^{\dagger}$ College of Chemistry and Chemical Engineering, Taiyuan University of Technology, Taiyuan 030024, China

$\$$ School of Chemical Engineering and Light Industry, Guangdong University of Technology, Guangzhou 510006, China

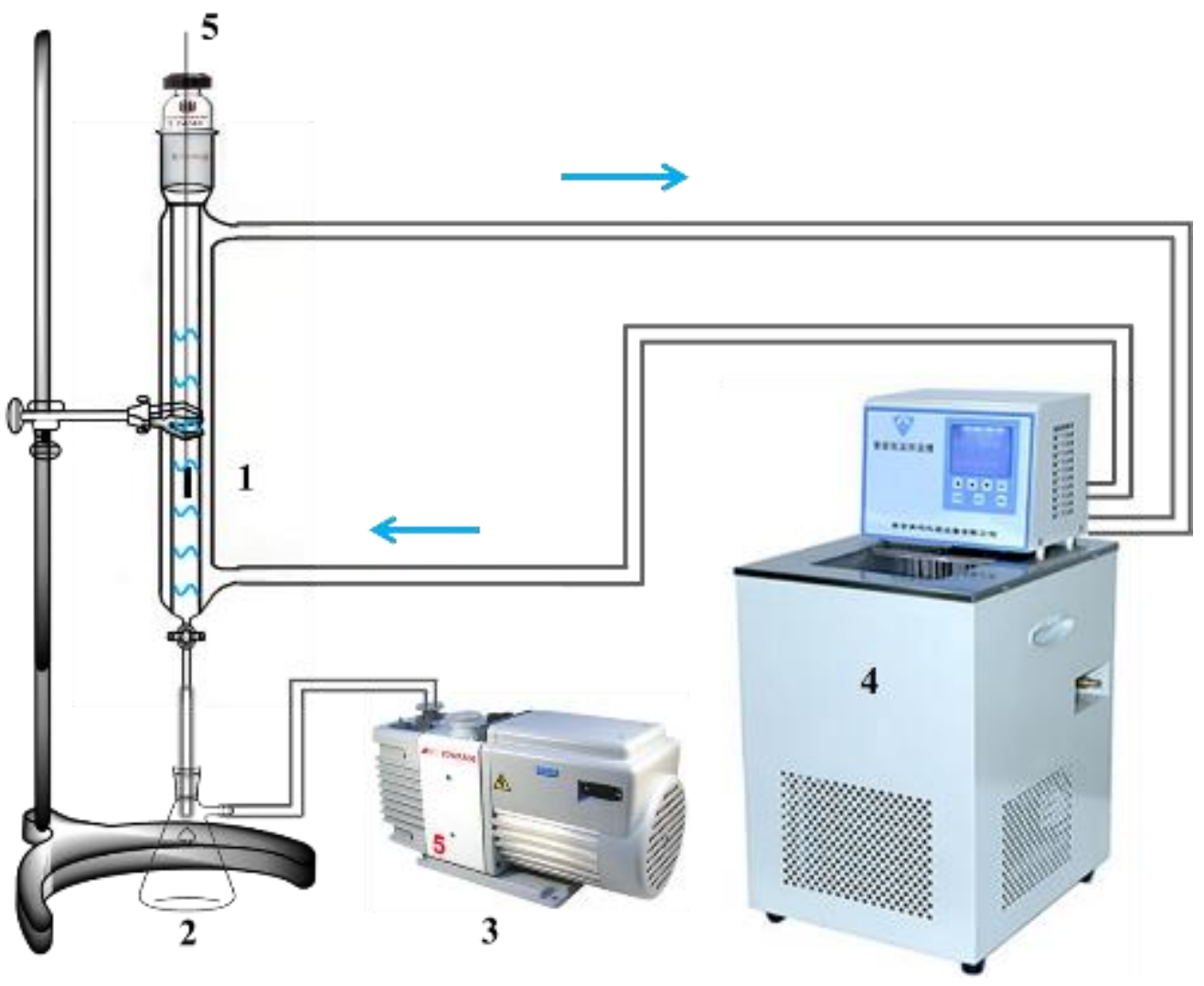

Figure S1. A schematic illustration of the melt crystallization equipment: (1) jacketed crystal tube, (2) collection bottle, (3) vacuum pump, (4) cryostat and (5) thermocouple. 
The crystal tube was divided into two layers, the inner tube placement melt with an outside diameter of $22 \mathrm{~mm}$ and the outer jacket with an outside diameter of $45 \mathrm{~mm}$ and a length of $300 \mathrm{~mm}$, which was used to circulate the cooling medium (anhydrous ethanol). The melt exchanged heat with the outer circulating medium through a glass wall with a thickness of $1.8 \mathrm{~mm}$. The temperature of the coolant was controlled by a cryostat (DHX-6008, Nanjing Karma Instrument Equipment Co., Ltd.) with programmable temperature control and the coolant was delivered via a hose at a flow rate of $16 \mathrm{~L} \cdot \mathrm{min}^{-1}$. The bottom of the crystallization tube was connected to a vacuum pump (Edwards RV 5) via a Teflon plug and collection bottle. The temperature change in the melt in the inner tube was recorded using a precise thermocouple.

Table S1. The parameters used in the further separation process of EG/BDO

\begin{tabular}{cccccc}
\hline Steps & $T_{\text {ict }}\left({ }^{\circ} \mathrm{C}\right)$ & $T_{\text {fct }}\left({ }^{\circ} \mathrm{C}\right)$ & $m_{\mathrm{ml}}(\mathrm{g})$ & $T_{\mathrm{sw}}\left({ }^{\circ} \mathrm{C}\right)$ & $m_{\mathrm{sw}}(\mathrm{g})$ \\
\hline II-1 & -15 & -17 & 9.669 & - & - \\
II-2 & -15 & -16.5 & 8.254 & - & - \\
II-3 & -15 & -17 & 7.604 & -14.5 & 10.479 \\
III-1 & -14.5 & -16.5 & 5.115 & - & - \\
III-2 & -14.5 & -15.5 & 9.809 & - & - \\
III-3 & -14.5 & -15.5 & 8.737 & -13.5 & 11.444 \\
\hline
\end{tabular}

Table S2. Separation parameters used in the removal of PDO from EG

\begin{tabular}{llllll}
\hline Steps & $T_{\text {ict }}\left({ }^{\circ} \mathrm{C}\right)$ & $T_{\text {fct }}\left({ }^{\circ} \mathrm{C}\right)$ & $m_{\mathrm{ml}}(\mathrm{g})$ & $T_{\text {sw }}\left({ }^{\circ} \mathrm{C}\right)$ & $m_{\mathrm{sw}}(\mathrm{g})$ \\
\hline
\end{tabular}




\begin{tabular}{cccccc}
\hline I & -16 & -19 & 13.246 & -16 & 24.355 \\
II-1 & -16 & -19 & 5.89 & - & - \\
II-2 & -15.5 & -18.5 & 4.855 & - & - \\
II-3 & -15 & -18 & 4.513 & -14.2 & 20.336 \\
III-1 & -14.5 & -17 & 7.391 & - & - \\
III-2 & -14.5 & -16.5 & 6.607 & - & - \\
III-3 & -14.5 & -16.5 & 4.152 & -13.5 & 15.427 \\
\hline
\end{tabular}

